\title{
2,202 Kidney Transplant Recipients with 10 Years of Graft Function: What Happens Next?
}

\author{
Arthur J. Matas, MD, Kristen J. Gillingham, PhD, Abhinav Humar, MD, Raja Kandaswamy, \\ MD, David E. R. Sutherland, MD, PhD, William D. Payne, MD, Ty B. Dunn, MD, and John S. \\ Najarian, MD \\ Department of Surgery, University of Minnesota
}

\begin{abstract}
The ultimate goal of clinical transplantation is for the recipients to achieve long-term survival, with continuing graft function, that is equivalent to that of the age-matched general population. We studied subsequent outcome in kidney transplant recipients with 10 years of graft function. In all, 2,202 kidney transplant recipients survived with graft function $>10$ years. For 10-year survivors, the actuarial 25-year patient rate for primary transplant living donor (LD) recipients was 57\%; graft survival, 43\%. For primary transplant deceased donor (DD) recipients, the actuarial 25 year patient survival rate was 39\%; graft survival, 27\%. The 2 major causes of late graft loss were death (with graft function) and chronic allograft nephropathy (tubular atrophy and interstitial fibrosis). The 2 major causes of death with function were cardiovascular disease (CVD) and malignancy. For nondiabetic recipients, the mean age at death with function from CVD was $54 \pm 13$ years; for diabetic recipients, $53 \pm 7$ years. By 20 years posttransplant, morbidity was common: $>40 \%$ recipients had skin cancer (mean age for nondiabetic recipients, $53 \pm 13$ years; for diabetics, $49 \pm 8$ years), $>10 \%$ had non-skin cancer (mean age for nondiabetic recipients, $53 \pm 16 y e a r s$; for diabetics, $46 \pm 9$ years), and $>30 \%$ had CVD (mean age for nondiabetic recipients, $53 \pm 15$ years; for diabetics, $47 \pm 9$ years). We conclude that long-term transplant recipients have a high rate of morbidity and early mortality. As short-term results have improved, more focus is needed on longterm outcome.
\end{abstract}

\section{Keywords}

kidney; graft loss; outcomes

For patients with end-stage renal disease (ESRD), a successful transplant (as compared with dialysis) provides significantly higher survival rates and better quality of life $(1,2)$.

However, although the transplant may correct ESRD, recipients still may suffer the adverse effects of their previous longstanding ESRD, and often of their years on dialysis. In addition, recipients with long-term graft survival bear the burden of prolonged immunosuppression and its consequences; those with even mildly abnormal kidney function are likely to be at increased risk for cardiovascular disease (3).

Most research on kidney transplant outcome has focused on the 1st decade posttransplant. Now that short-term results have improved and more patients with ESRD are opting for a transplant, more are surviving with functioning grafts into the 2nd and 3rd decades posttransplant. It is important to identify areas of concern for these recipients. If specific

Address correspondence to: Arthur J. Matas, MD, MMC 328, 420 Delaware St. SE, Minneapolis, MN 55455. Phone: 612-625-6460, Fax 612-624-7168, e-mail: matas001@umn.edu. 
problem areas can be identified, they can be addressed in future prospective studies. Herein, we studied long-term outcome for recipients with $\geq 10$ years of graft function. We grouped the recipients into Era 1, those transplanted through December 31, 1983 (who for the most part did not receive calcineurin inhibitor [CNI]-based immunosuppression) and Era 2, those transplanted on or after January 1, 1984 (who did receive CNI-based immunosuppression).

\section{Methods}

From June 7, 1963, through June 30, 1997, a total of 4,714 kidney transplants (2373 LD, 2341 DD) were done at the University of Minnesota and had potential graft survival time $\geq 10$ years. Immunosuppressive protocols have been described in detail (4). In brief, prior to 1984, maintenance immunosuppression was prednisone and azathioprine; after 1984, maintenance was CNI - based. Recipient information was kept on our computer database. Detailed information, including on AR episodes and on pre- and posttransplant comorbidities, was available for recipients transplanted on or after January 1, 1984. Less complete information was available for recipients transplanted earlier. For the purpose of our analyses, we have subgrouped recipients into Era 1 (1/1/1963 through 12/31/1983 preCNI; basic information in the database) $(n=1990 ; 1126$ LD, 864DD) and Era 2(1/1/1984 through 6/30/1997; CNI-based immunosuppression; detailed information in the database) (n $=2724 ; 1247 \mathrm{LD}, 1477 \mathrm{DD})$.

Following discharge, recipients return to the care of their primary physician or nephrologists. Lab work is initially done 3 times per week and then tapered over the next 2 years so that clinically well recipients are having lab work done every 1-2 months. Although there is no official subsequent taper, long-term recipients often get lab work done every 4-6 months (less frequently for some). Our policy is to follow the recipients'

immunosuppression and transplant-related issues indefinitely. For those not cared for at our institution, we request that all laboratory studies are called or faxed to our Transplant Center and reviewed by a coordinator. All lab work and intercurrent illnesses are documented in the recipients' chart. Adjustments may then be made to immunosuppressive protocols.

Recipients with transplant-related abnormal labs (e.g., elevated serum creatinine level) return to our center (usually after a confirmatory lab study) for further evaluation. In addition, recipients whose primary care is not at our institution are asked to return annually for evaluation. If they are unable to return for an annual posttransplant care visit, we ask for the documentation of their local physician annual visit.

Prior to 1988, basic recipient information, including date and cause of graft loss and date and cause of death was kept for all recipients. In 1988, began prospectively collecting detailed information on all recipients. At that time, we decided to retrospectively collect detailed information on all transplants since 1984 (when all recipients were first on calcineurin inhibitor-based immunosuppression). For recipients transplanted before 1984, and who were alive with function in 1984, we collected detailed follow-up data; for those who had lost function or died prior to 1984, we did not get additional information.

The detailed information is collected for recipients who have given consent to be part of the research database project; information required by UNOS is collected for all recipients. When additional information is required (e.g., records from another hospital) we obtain permission from the recipient.

Database coordinators make rounds on the transplant ward on a regular basis. Information on any readmission is entered into the computer database. In addition, data coordinators review recipients' outpatient charts every 6 months. Lab work, any readmissions at other institutions, and any new comorbidities are entered into the computer database. We also 
send an annual letter to all recipients asking them to provide us with information on hospitalizations, intercurrent illnesses, or diagnoses (at other institutions or by their local physician).

Recipients who have not contacted us for 2 years are considered "lost to follow-up". The research team devotes extra effort to contacting these patients. First, we run their information through the Social Security Master Death Index. If there is no evidence that they have died, we then to attempt to contact them by phone.

If we identify a recipient as having died, we attempt to get records from the admitting hospital, the primary physician, the coroner, or the health department. Records are reviewed and the cause of death determined and entered into the database. In the absence of records, the family is contacted and asked the cause(s) of death. A similar approach is taken for graft loss. If a biopsy or nephrectomy has been done, the information is entered into the database. If a recipient with chronic graft deterioration has a biopsy and the graft subsequently fails (even years later) without another biopsy, the diagnosis made at biopsy is presumed to be the cause of graft loss.

For recipients with comorbidities (e.g., malignancy) we obtain the medical records and pathology reports.

Definitions have been developed for cause of death and for cause of graft failure. This permits consistency among multiple data personnel. Each is a "choice field" rather than a "text field" in the database so the data is in an analyzable format. The definitions for cause of death have remained stable over time. However, the definitions and categories for cause of graft loss have changed. For example, graft loss after a period of slow graft deterioration was classified as "chronic rejection, biopsy-proven" if a biopsy was done, "chronic rejection, not biopsy-proven" if no biopsy was done. More recently, calcineurin-related nephrotoxicity, chronic allograft nephropathy (CAN), and Banff scores were added to the database. In addition, we are now much more aggressive about biopsying a graft with slow deterioration of function. Historically, much of the "chronic rejection" or "CAN" was presumed.

For recipients with $\geq 10$ years of graft function, we calculated subsequent actuarial patient, graft, and death-censored graft survival rates. All survival information is censored at the date of last follow-up. We compared actuarial outcome for Era 1 vs. Era 2; we also compared causes of graft loss and causes of death. Graft loss was defined as return to chronic dialysis, graft removal, a retransplant, or death, whichever came first. Causes of death were determined for recipients dying with graft function (we did not follow recipients who had returned to dialysis). We also compared causes of events (graft loss or death) occurring from 10 to 15 years posttransplant, from 15 to 20 years posttransplant, and $\geq 20$ years posttransplant.

Using multivariate analysis, we studied risk factors for graft loss in the first 10 years posttransplant. Similarly, for recipients with $\geq 10$ years of graft function, we studied risk factors for subsequent graft loss. Risk factors included in the analyses are shown in Table 1a. For analyses done on the Era 2 population (for whom we have more detailed information), we included additional risk factors (Table 1b). For Era 2 recipients who survived $\geq 10$ years, we studied the development of these posttransplant comorbidities: malignancy, cardiovascular disease (CVD), CVA, and peripheral vascular disease.

To calculate patient and graft survival rates, we used actuarial techniques. To compare between groups, we used a generalized Wilcoxon test. For the Era 2 recipients, pre- or posttransplant CVD included a history of angina, cardiac arrest requiring defibrillation, 
arrhythmia, documented coronary artery disease, cardiomyopathy, congestive heart failure, myocardial infarct, or valve dysfunction. Pre- or posttransplant CVA included a history of stroke, intracerebral bleed, or transient ischemic attack. Pre- or posttransplant peripheral vascular disease included a history of claudication, documented occlusion or stenosis of a major artery, aneurysm or pseudoaneurysm, or amputation.

\section{Results}

Of the 4,714 transplants, a total of 2,202 (46.7\%) (1,330 LD; 872 DD) resulted in graft function $\geq 10$ years (as of July 1, 2007). Of these 2,202, 45 (2\%) have been lost to follow-up - i.e., we have no data in the last 2 years. Of the 45,34 have lost their graft (date and cause of graft loss are entered into the database) and 9 have presumed graft function. As noted above, all survival data is censored at date of last follow-up.

Ten-year actual graft survival was significantly better for Era 2 (50\%) vs. Era 1 (42\%) recipients ( $\mathrm{p}<.0001)$. Of the 835 survivors in Era 1, 571 were LD recipients, 264 DD; of the 1,367 in Era 2, 759 were LD recipients, 608 DD.

\section{Risk factors for graft loss in the first $\mathbf{1 0}$ years}

For the 4,714 recipients, risk factors for graft loss in the first 10 years posttransplant were: use of a DD ( $\mathrm{p}<.0001)$, a retransplant ( $\mathrm{p}<.0001)$, a transplant after initiation of dialysis $(\mathrm{p}<$. 0001), $\geq 3$ antigen HLA mm ( $\mathrm{p}<.0001)$, black ethnicity $(\mathrm{p}=.04)$, age at transplant $\geq 50(\mathrm{p}<$. 0001), and immunosuppressive protocol 3, 4, or 5 (vs. protocol 1) ( $\mathrm{p}=.03$ ) or protocol 2 (vs. protocol1) $(\mathrm{p}=.06)$.

For Era 2 recipients (for whom AR and comorbidities could also be included in our analysis), additional risk factors for graft loss in the first 10 years were: $\geq 1$ AR episode ( $p<$. 0001), pretransplant CVA ( $\mathrm{p}=.0002)$, pretransplant peripheral vascular disease $(\mathrm{p}<.005)$, and pretransplant liver disease $(\mathrm{p}<.03)$.

\section{Actuarial survival rates after 10 years}

Characteristics of the 2,202 recipients with $\geq 10$ years of graft function are shown in Table 2 . For primary LD recipients with $\geq 10$ years of graft function, the 25 -year actuarial patient survival rate was 57\%; for retransplant LD recipients, 69\% (Figure 1a). For primary DD recipients with graft survival $\geq 10$ years, the 25 -year patient survival rate was $39 \%$; for retransplant DD recipients, $34 \%$. For both primary and retransplant recipients, the actuarial patient survival rate after 10 years was significantly better for $L D$ recipients than for DD recipients ( $\mathrm{p}<.001)$. For Era 2 primary $L D$ recipients who survived $\geq 10$ years, their subsequent survival rate was significantly better than for their Era 1 counterparts ( $\mathrm{p}<.0001)$; we found no difference between eras for primary DD recipients or for retransplant recipients. Of 10 -year survivors, about $4 \%( \pm .02 \%)$ of the primary LD recipients died each year thereafter; of the primary DD recipients, about $6 \%( \pm .02 \%)(\mathrm{p}<.0001)$; of the retransplant $\mathrm{LD}$ recipients, $3 \%( \pm .02 \%)$; and of the retransplant $\mathrm{DD}$ recipients, $7 \%( \pm .03 \%)$ $(\mathrm{p}=.0006)$.

For primary LD recipients with $\geq 10$ years of graft function, the 25 -year actuarial graft survival rate was $43 \%$; for retransplant LD recipients, $48 \%$ (Figure 1b). For primary DD recipients with $\geq 10$ years of graft function, the 25 -year actuarial graft survival rate was $27 \%$; for retransplant DD recipients, $15 \%$. For both primary and retransplant recipients, the actuarial graft survival rate after 10 years was significantly better for LD recipients than for DD recipients $(\mathrm{p}<.0001)$. However, for 10-year survivors, we found no difference, by era, in the subsequent graft survival rates. After 10 years, the average annual rate of graft loss for primary $\mathrm{LD}$ recipients was $5 \%( \pm .01 \%)$; for primary DD recipients, $9 \%( \pm .01 \%)(\mathrm{p}<.0001)$; 
for retransplant LD recipients, $5 \%( \pm .03 \%)$; for retransplant DD recipients, $11 \%( \pm .03 \%)$ $(\mathrm{p}<.0001)$.

For primary LD recipients with $\geq 10$ years of graft function, the 25 -year actuarial deathcensored graft survival rate was $70 \%$; for retransplant LD recipients, $61 \%$ (Figure 1c). For primary DD recipients with $\geq 10$ years of graft function, the actuarial 25 -year death-censored graft survival rate was 57\%; for retransplant DD recipients, 34\%. For both primary and retransplant recipients, the actuarial death-censored graft survival rate after 10 years was significantly better for $\mathrm{LD}$ recipients than for DD recipients ( $<$ <.001). For Era 2 primary LD recipients who survived $\geq 10$ years, their subsequent death-censored graft survival rate was significantly better than for their Era 1 counterparts ( $p<.03)$; we found no difference between eras for primary DD recipients or for retransplant recipients. After 10 years, the average annual rate of death-censored graft loss for primary LD recipients was $2 \%( \pm .01 \%)$; for primary DD recipients, $4 \%( \pm .01 \%)(\mathrm{p}=\mathrm{NS})$; for retransplant $\mathrm{LD}$ recipients, $3 \%( \pm .03 \%)$; and for retransplant DD recipients, $6 \%( \pm .03 \%)(\mathrm{p}=.003)$.

\section{Cause of graft loss and death with function after 10 years}

Most graft losses after 10 years posttransplant were due to patient death and to chronic rejection (now called tubular atrophy and interstitial fibrosis [TA/IF]) (6) (Table 3). The primary causes of late graft loss did not differ between primary and retransplant recipients, between LD and DD recipients, or by eras (Table 4). We also studied primary cause of graft loss by 5 -year intervals (10 through 14 years; 15 through 19 years; 20 through 24 years posttransplant), and found no significant differences between these 3 groups (Table 5).

The causes of death for recipients who died with graft function are shown in Table 6. CVD, malignancy, and infection were the 3 major causes of death with function. We found no difference by donor source. Similarly, when studying causes of death in 5-year intervals, we found no difference by donor source (Table 7).

We compared the mean age at death for recipients who died of specific causes (Table 8) and for recipients with vs. without diabetes as a cause of their primary kidney failure. We found no significant difference between these groups, but noted a trend $(\mathrm{p}=.08)$ toward a lower mean age of death from CVA in recipients with diabetes.

We also studied the mean creatinine level at death for recipients who died of specific causes (although we did not have a recent creatinine level [i.e., within 1 year before death], for all recipients) (Table 8). For recipients who died with graft function, the mean creatinine level was $1.8( \pm 1.0)$. For recipients still alive with continued graft function at the end of our study, the mean creatinine level per their most recent report was $1.7( \pm 1.0)$.

\section{Risk factors for graft loss after 10 years}

For the 2,202 recipients with 10-year graft function, risk factors for graft loss after 10 years included age at transplant $\geq 50(\mathrm{p}<.0001)$, a transplant before initiation of dialysis $(\mathrm{p}<$. 0001 ), type 1 diabetes ( $\mathrm{p}<.0001)$, use of a DD ( $\mathrm{p}=.002), \geq 3$ antigen HLA mm ( $\mathrm{p}=.002)$, and a retransplant $(\mathrm{p}=.03)$.

For Era 2 recipients (for whom AR and comorbidities could also be included in our analysis), additional risk factors for graft loss after 10 years were as follows: 1 AR episode $(\mathrm{p}=.003),>1$ AR episode $(\mathrm{p}<.0001)$, pretransplant CVD $(\mathrm{p}=.02)$, pretransplant peripheral vascular disease $(\mathrm{p}<.04)$, and pretransplant liver disease $(\mathrm{p}<.02)$. 


\section{Renal Function}

Mean serum creatinine level $( \pm \mathrm{SD})$ is shown for 10-year survivors in Table 9. Those with $\geq 1$ AR episode had significantly higher creatinine levels than those without AR (data not shown) (p<.0001).

Comorbidities after 10 years-For Era 2 recipients with $\geq 10$-year graft function (for whom we have data on long-term morbidity), morbidity was common. We focused on these 2 main causes of comorbidity:

1. Malignancy: By 20 years posttransplant, nearly $50 \%$ of recipients had $\geq 1$ skin cancer (Table 10). The rates differed significantly between LD and DD recipients $(\mathrm{p}<.05)$. The mean age on diagnosis $( \pm$ SE) of skin cancer for nondiabetic recipients $(n=245)$ was $53 \pm 13$ years (range, 13 to 81 ); for diabetic recipients ( $\mathrm{n}=155), 49 \pm 8$ years (range, 28 to 69$)(\mathrm{p}=$. 003).

By 20 years posttransplant, over $10 \%$ of recipients had a non-skin, non-PTLD malignancy. DD recipients (both diabetic and nondiabetic) had significantly higher cancer rates than LD recipients ( $\mathrm{p}<.05)$. The mean age $( \pm \mathrm{SE})$ on diagnosis of non-skin, non-PTLD cancer for nondiabetic recipients ( $\mathrm{n}=93$ ) was $53 \pm 16$ years (range, 11 to 78 ); for diabetic recipients $(\mathrm{n}=60), 46 \pm 9$ years (range, 28 to 65$)(\mathrm{p}=.0007)$.

By 20 years posttransplant, over $2 \%$ of recipients developed PTLD. We observed a suggestion of higher rates in DD recipients $(\mathrm{p}=\mathrm{NS})$. The mean age $( \pm \mathrm{SE})$ on diagnosis of PTLD for nondiabetic recipients ( $\mathrm{n}=20$ ) was $47 \pm 20$ years (range, 5 to 79 ); for diabetic recipients ( $\mathrm{n}=18), 49 \pm 8$ years (range, 38 to 68$)(\mathrm{p}=\mathrm{NS}$ ).

\section{Cardiovascular disease}

i. Heart: By 20 years posttransplant, over 25\% of recipients developed CVD disease (Table 6). For nondiabetics, LD recipients had significantly less heart morbidity than DD recipients $(\mathrm{p}<.05)$. But for diabetics, we found no difference. The overall heart disease-free survival rate was higher for nondiabetics than for diabetics $(\mathrm{p}<.05)$. The mean age $( \pm \mathrm{SE})$ on first diagnosis of posttransplant CVD for nondiabetic recipients $(\mathrm{n}=175)$ was $53 \pm 15$ years (range, 3 to 79); for diabetic recipients ( $\mathrm{n}=206), 47 \pm 9$ years (range, 22 to 76$)(\mathrm{p}<.0001)$.

ii. CVA: By 20 years posttransplant, over $5 \%$ of recipients developed cerebrovascular disease (Table 6). For nondiabetics, LD recipients had significantly lower CVA rates than DD recipients $(\mathrm{p}<.05)$; for diabetics, we found no difference. The CVA-free survival rate was higher for nondiabetics than for diabetics $(\mathrm{p}<.05)$. The mean age $( \pm \mathrm{SE})$ on diagnosis of CVA for nondiabetic recipients $(\mathrm{n}=42)$ was $58 \pm 14$ years (range, 9 to 79$)$; for diabetic recipients $(\mathrm{n}=81), 48 \pm 10$ years (range, 20 to 75$)(\mathrm{p}<.003)(28-69)$.

iii. Peripheral vascular disease: By 20 years posttransplant, over $12 \%$ of recipients developed peripheral vascular disease. We found no difference between LD and DD recipients. However, nondiabetics had less peripheral vascular disease than diabetics ( $p<$. $05)$. The mean age $( \pm \mathrm{SE}$ ) on diagnosis of peripheral vascular disease for nondiabetic recipients ( $\mathrm{n}=86$ ) was $50 \pm 15$ years (range, 6 to 77 ); for diabetic recipients ( $\mathrm{n}=136), 47 \pm 9$ years (range, 25 to 76$)(\mathrm{p}=.004)$.

\section{Discussion}

Early in the history of transplantation, the major focus of clinical research was improving immunosuppressive protocols to minimize AR episodes and to maximize short-term 
recipient and graft survival. Only in the last 15 years has short-term outcome improved sufficiently so that we can turn our attention to long-term issues.

National registry reports have not focused on outcome after the $1^{\text {st }}$ decade, although, in some studies, long-term graft survival has been reported (7-10). Despite ongoing concern about the consequences of immunosuppression, there have been few reports on both longterm morbidity and mortality (11-16). Webster et al., using the Australia and New Zealand Dialysis and Transplant (ANZDATA) registry (complete since 1963), recently reported on the cumulative risk of cancer for kidney recipients in the $1^{\text {st }} 20$ years posttransplant (11). They noted that, for kidney recipients, cancer rates were similar to those of nontransplanted people 20 to 30 years older. Recently, in an analysis of results from 2 centers, Vanrenterghem et al noted that 15 years posttransplant $53 \%$ of recipients had developed a cardiovascular complication (defined as CVD, CVA, or peripheral vascular disease) (16).

Using our single-center database, we found that 10 -year survivors had a relatively steady rate of graft loss, greater in DD than LD recipients (Figure 1). Some of this graft loss was due to "death with function," which is to be expected as the population ages. However, the mean age of our recipients at the time of death with function was $55 \pm 13$ years (Table 8).

Many of the risk factors for graft loss that we identified are not modifiable (e.g., age at transplant). However, some are determined at transplant or shortly thereafter. Modifiable risk factors for graft loss in the $1^{\text {st }} 10$ years included use of a DD, a transplant after initiation of dialysis, $\geq 3$ antigen HLA mm, the type of immunosuppressive protocol, and $\geq 1$ AR episode. After 10 years, the same modifiable risk factors were operative; in addition, pretransplant comorbidities were significant.

Some of these factors are interrelated. For DD candidates, waiting for a transplant (usually while on dialysis), is associated with significant morbidity and mortality. A preemptive transplant can often be done when LDs are available. Our data would suggest that increasing the use of LDs and minimizing AR episodes will have significant long-term effects (17-19).

We have previously noted that the 2 major causes of graft loss after the 1 st year were death with function and TA/IF (20). We now show that these 2 entities continue to be the major causes of graft loss through 25 years posttransplant, accounting for $>80 \%$ late graft losses. The 3 major causes of death with function were CVD, malignancy, and infection. In addition, the mean age at death for each of these causes was $<60$. Although the numbers in our subgroups are relatively small, our findings support development of protocols to minimize TA/IF and death with function from CVD, malignancy, and infection.

The ongoing risk for development of posttransplant malignancy and the relatively young age at onset of malignancy has previously been described (9). We also noted the ongoing risk and the relatively young age at onset of cardio-, cerebro-, and peripheral vascular complications. Vanrenterghem et al recently reported the common occurrence and risk factors for these complications posttransplant (16). Although cardiovascular risk is lower after a transplant (vs. on maintenance dialysis) (21), our findings suggest the importance of continued aggressive prevention strategies.

A limitation of our analysis is that the long-term outcome of our recipient population reflects the immunosuppressive protocols used at the time of transplant. Even these changed during our study—from no CNI before 1984 to increased use of CNI after 1984. And maintenance immunosuppressive protocols have changed significantly since the mid 1990s with the introduction of mycophenolate mofetil, tacrolimus, and sirolimus. Currently, most kidney transplant recipients in the United States receive tacrolimus and mycophenolate mofetil (with or without prednisone) for maintenance immunosuppression (22). Newer protocols 
may be associated with improved long-term outcome. Acute rejection rates are lower now than prior to 1997. Vanrenterghem et al. noted that long-term prednisone use was associated with increased CVD risk (16); many current protocols incorporate prednisone-free maintenance immunosuppression $(22,23)$. Elevated serum creatinine level is a risk factor for posttransplant CVD (24); newer protocols attempt to preserve renal function $(25,26)$.

A second limitation is that transplants with "creeping creatinine" and chronic dysfunction were often not biopsied. Thus, we may have understated the incidence of graft loss to recurrent or de novo disease, or to calcineurin inhibitor toxicity. For 10- year survivors, we found no difference, by era, in subsequent graft survival. For LD recipients with $\geq 10$ year survival, the subsequent death-censored graft survival was significantly better in era 2 vs. era $1(\mathrm{p}<.03)$; there was no difference for DDs. Thus we did not see the impaired long-term graft survival, noted by Gallagher et al, in calcineurin inhibitor-treated recipients (27). Gallagher et al randomized recipients to maintenance azathioprine plus prednisone vs. cyclosporine monotherapy vs. cyclosporine for 3 months and then conversion to azathioprine plus prednisone. The cyclosporine treated group did better initially; but longterm graft survival was better in the group converted to azathioprine.

A third limitation is that it would have been ideal to compare the mean age at onset of, and the mean age at death from, each of the comorbidities we studied vs. the mean age in the age-matched general population (as was done for malignancy in the ANZDATA registry), but our sample size was not large enough. A fourth limitation is our use of actuarial (vs. actual) survival after 10 years. Meier-Kriesche et al, studying transplant data analyses have noted that actual outcomes may vary form projected outcomes (28).

This study is the first cross-sectional single-center look at long-term outcome for 10-year kidney transplant survivors. We identified ongoing graft and recipient loss and development of comorbidities at a relatively young age. Our study emphasizes the need for development of a comprehensive program for care of kidney recipients with ESRD, including early consideration of a transplant, use of an $\mathrm{LD}$, development of immunosuppressive protocols to minimize rejection and morbidity, and long-term focus on the prevention, early diagnosis, and treatment of comorbidities.

\section{Acknowledgments}

We thank Mary Knatterud for editorial assistance and Stephanie Daily for preparation of the manuscript.

Supported by NIH Grant \#13083

\section{References}

1. Wolfe RA, Ashby VB, Mitford EL, Ojo AO, Ettenger RE, Agodoa LYC, et al. Comparison of mortality in all patients on dialysis, patients on dialysis awaiting transplantation, and recipients of a first cadaveric transplant. N Engl J Med. 1999; 341:1725-1730. [PubMed: 10580071]

2. Evans RW, Manninen DL, Garrison LP Jr, Hart LG, Blagg DR, Gutman RA, et al. The quality of life of patients with end-stage renal disease. N Engl J Med. 1985; 312(9):553-9. [PubMed: 3918267]

3. Meier-Kriesche HU, Baliga R, Kaplan B. Decreased renal function is a strong risk factor for cardiovascular death after renal transplantation. Transplantation. 2003; 75(8):1291-5. [PubMed: 12717218]

4. Matas AJ, Sutherland DE, Najarian JS. Evolution of immunosuppression at the University of Minnesota. Transplant Proc. 2004; 36(2 Suppl):64S-70S. [PubMed: 15041309]

5. Dunn DL, Gillingham KJ, Kramer MA, Schmidt WJ, Erice A, Balfour HH Jr, et al. A prospective randomized study of acyclovir versus gangiclovir plus human immune globulin prophylaxis of 
cytomegalovirus infection after solid organ transplantation. Transplantation. 1994; 57(6):876-84. [PubMed: 8154035]

6. Racusen LC, Solez K, Colvin RB, Bansib SM, Castro MC, Cavallo T, et al. The Banff 97 working classification of renal allograft pathology. Kidney Int. 1999; 55:713-723. [PubMed: 9987096]

7. Cecka, JM. The UNOS scientific renal transplant registry-2000. In: Cecka, JM.; Terasaki, PI., editors. Clinical Transplants. Los Angeles, CA: UCLA Tissue Typing Laboratory; 2000. p. 1-18.

8. Arend SM, Mattat MJK, Westendorp RJW, van der Woude FJ, van Es LA. Patient survival after renal transplantation; more than 25 years follow-up. Nephrol Dial Transplant. 1997; 12(8):1672-9. [PubMed: 9269647]

9. Tangeraas T, Bjerre A, Lien B, Kyte A, Monn E, Cvancarova M, et al. Long-term outcome of pediatric renal transplantation: The Norwegian experience in three eras 1970-2006. Pediatr Transplant. 2008 Jan 14. Epub ahead of print.

10. Gheith OA, Bakr MA, Fouda MA, Shokeir AA, Sobh M, Ghoneim M. Prospective randomized study of azathioprine vs. cyclosporine based therapy in primary haplo-identical living-donor kidney transplantation: 20-year experience. Clin Exp Nephrol. 2007; 11:151-155. [PubMed: 17593515]

11. Webster AC, Craig JC, Simpson JM, Jones MP, Chapman JR. Identifying high risk groups and quantifying absolute risk of cancer after kidney transplantation: A cohort study of 15,183 recipients. Am J Transplant. 2007; 7:2140-2151. [PubMed: 17640312]

12. Bordea C, Wojnarowska F, Millard PR, Doll H, Welsh K, Morris PJ. Skin cancers in renaltransplant recipients occur more frequently than previously recognized in a temperate climate. Transplantation. 2004; 77(4):574-579. [PubMed: 15084938]

13. Faull RJ, Hollett P, McDonald SP. Lymphoproliferative disease after renal transplantation in Australia and New Zealand. Transplantation. 2005; 80(2):193-7. [PubMed: 16041263]

14. Bordea C, Wojnarowska F, Millard PR, Doll H, Welsh K, Morris PJ. Skin cancers in renaltransplant recipients occur more frequently than previously recognized in a temperate climate. Transplantation. 2004; 77(4):574-9. [PubMed: 15084938]

15. London NJ, Farmery SM, Will EJ, Davison AM, Lodge JP. Risk of neoplasia in renal transplant patients. Lancet. 1995; 346(8972):403-6. [PubMed: 7623570]

16. Vanrenterghem YFC, Claes K, Montagnino G, Fieuws S, Maes B, Villa M, et al. Risk factors for cardiovascular events after successful renal transplantation. Transplantation. 2008; 85(2):209-216. [PubMed: 18212625]

17. Cosio FG, Alamir A, Yim S, Pasavento TE, Falkenhain ME, Henry ML, et al. Patient survival after renal transplantation: I. The impact of dialysis pre-transplant. Kidney Int. 1998; 53:767-772. [PubMed: 9507225]

18. Mange KC, Joffe MM, Feldman HI. Effect of the use or nonuse of long-term dialysis on the subsequent survival of renal transplants from living donors. N Engl J Med. 2001; 344:726-731. [PubMed: 11236776]

19. Meier-Kriesche HU, Kaplan B. Waiting time on dialysis as the strongest modifiable risk factor for renal transplant outcomes-A paired donor kidney analysis. Transplantation. 2002; 74:1377-1381. [PubMed: 12451234]

20. Matas AJ, Humar A, Gillingham KJ, Payne WD, Gruessner RW, Kandaswamy R, et al. Five preventable causes of kidney graft loss in the 1990s: a single-center analysis. Kidney Int. 2002; 62(2):704-14. [PubMed: 12110036]

21. Meier-Kriesche HU, Schold JD, Srinivas TR, Reed A, Kaplan A. Kidney transplantation halts cardiovascular disease progression in patients with end-stage renal disease. Am J Transplant. 2004; 4(10):1662-8. [PubMed: 15367222]

22. Excerpts from the United States Renal Data System. 2007 Annual Data Report: Atlas of Chronic Kidney Disease \& End-Stage Renal Disease in the United States. AJKD. 2008; 51(1, suppl 1):S169.

23. Matas AJ, Kandaswamy R, Gillingham KJ, McHugh L, Ibrahim H, Kasiske B, et al. Prednisonefree maintenance immunosuppression - a 5-year experience. Am J Transplant. 2005; 5(10):24738. [PubMed: 16162197] 
24. Meier-Kriesche HU, Baliga R, Kaplan B. Decreased renal function is a strong risk factor for cardiovascular death after renal transplantation. Transplantation. 2003; 75(8):1291-5. [PubMed: 12717218]

25. Flechner SM, Kobashigawa J, Klintmalm G. Calcineurin inhibitor-sparing regimens in solid organ transplantation: focus on improving renal function and nephrotoxicity. Clin Transplant. 2008; 22(1):1-15. [PubMed: 18217899]

26. Grinyó JM, Cruzado JM. Mycophenolate mofetil and sirolimus combination in renal transplantation. Am J Transplant. 2006; 6:1991-9. [PubMed: 16930395]

27. Gallagher MP, Hall B, Craig J, Berry G, Tiller DJ, Eris J. Australian Multicenter Trial of Cyclosporine Withdrawal Study Group and the ANZ Dialysis and Transplantation Registry. A randomized controlled trial of cyclosporine withdrawal in renal-transplant recipients: 15-year results. Transplantation. 2004; 78:1653-60. [PubMed: 15591955]

28. Meier-Kriesche HU, Schold JD, Kaplan B. Long-term renal allograft survival: have we made significant progress or is it time to rethink our analytic and therapeutic strategies? Am J Transplant. 2004; 4:1289-95. [PubMed: 15268730] 

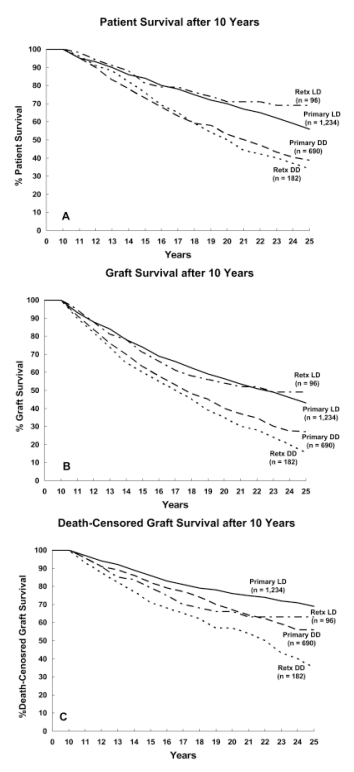

Figure 1.

Actuarial outcome for 2,202 kidney transplant recipients with 10 years of graft function (Era $1=835 ; 571 \mathrm{LD}, 264 \mathrm{DD})($ Era $2=1367 ; 759 \mathrm{LD}, 608 \mathrm{DD})$ : a) patient survival; b) graft survival; c) death-censored graft survival 
Table 1

\title{
Risk Factors in Multivariate Analyses
}

\author{
a) Factors included in all analyses \\ Donor source (LD vs. DD) \\ HLA mismatch (0-2 vs. 3-6) \\ Ethnicity (white, black, Asian, other) \\ Age ( $<18$ vs. $18-49$ vs. $\geq 50$ years) \\ Transplant number (primary vs. retransplant) \\ Recipient gender (male vs. female) \\ Type 1 diabetes (yes vs. no) \\ Immunosuppressive protocol \\ (all recipients transplanted during the 2 eras) \\ 1 - Antibody, prednisone, AZA $(\mathrm{n}=1726)$ \\ 2 - Antibody, prednisone, CSA, AZA ( $\mathrm{n}=1564)$ \\ 3 - Calcineurin inhibitor (CSA or tacrolimus), prednisone, AZA $(\mathrm{n}=802)$ \\ 4 - Calcineurin inhibitor (CSA or tacrolimus), prednisone, mycophenolate mofitil $(\mathrm{n}=36)$ \\ 5 - Antibody, calcineurin inhibitor (CSA or tacrolimus), prednisone, mycophenolate mofitil $(\mathrm{n}=124)$ \\ 6 - Other $(\mathrm{n}=183)$ \\ 7 - CSA, prednisone $(n=278)$
}

b) Additional factors included in analyses of the Era 2 Population

AR ( 1 episode vs. $0 ;>1$ episode vs. 0$)$,

pretransplant cardiovascular disease (CVD)(yes vs. no),

cerebrovascular accident (CVA) (yes vs. no),

peripheral vascular disease (yes vs. no),

liver disease (yes vs. no),

respiratory disease (yes vs. no).

pretransplant comorbidities (yes vs. no).

Legend: $\mathrm{AZA}=$ azathioprine

$\mathrm{CSA}=$ cyclosporine

$\mathrm{LD}=$ living donor

$\mathrm{DD}=$ deceased donor

HLA = human leukocyte antigen 
Table 2

Recipient Characteristics (10-year Transplant Survivors) $(\mathbf{n = 2 , 2 0 2})$

\begin{tabular}{|c|c|}
\hline \multicolumn{2}{|l|}{ Donor source } \\
\hline DD & $37 \%$ \\
\hline Related LD & $58 \%$ \\
\hline Unrelated LD & $3 \%$ \\
\hline \multicolumn{2}{|l|}{ Transplant number } \\
\hline Primary & $87 \%$ \\
\hline Mean age at transplant $( \pm \mathrm{SD})$ & $33 \pm 15$ \\
\hline Gender & $41 \%$ \\
\hline Female & $59 \%$ \\
\hline \multicolumn{2}{|l|}{ Male } \\
\hline \multicolumn{2}{|l|}{ Ethnicity } \\
\hline White & $96 \%$ \\
\hline Black & $2 \%$ \\
\hline American Indian & $1 \%$ \\
\hline Pretransplant diabetes & $28 \%$ \\
\hline \multicolumn{2}{|c|}{ Primary transplant recipients only } \\
\hline \multicolumn{2}{|l|}{ PRA at transplant } \\
\hline $0 \%$ & $82 \%$ \\
\hline $1-10 \%$ & $5 \%$ \\
\hline $11-50 \%$ & $7 \%$ \\
\hline$>50 \%$ & $6 \%$ \\
\hline \multicolumn{2}{|l|}{ Peak PRA } \\
\hline $0 \%$ & $73 \%$ \\
\hline $1-10 \%$ & $8 \%$ \\
\hline $11-50 \%$ & $9 \%$ \\
\hline$>50 \%$ & $10 \%$ \\
\hline
\end{tabular}

Legend:

$\mathrm{DD}=$ Deceased donor

$\mathrm{LD}=$ Living donor

PRA $=$ Panel-reactive antibody $(\%)$ 
Table 3

Primary Causes of Graft Loss after 10 Years, by Transplant Number and Donor Source (All Recipients)

\begin{tabular}{lcccc}
\hline & $\begin{array}{c}\text { Primary DD } \\
(\mathbf{n = 3 3 1})\end{array}$ & $\begin{array}{c}\text { Primary LD } \\
(\mathbf{n = 5 0 7})\end{array}$ & $\begin{array}{c}\text { Retransplant DD } \\
(\mathbf{n = 9 1})\end{array}$ & $\begin{array}{c}\text { Retransplant LD } \\
(\mathbf{n = 4 0})\end{array}$ \\
Acute rejection (AR), n (\%) & $2(.6 \%)$ & $5(1 \%)$ & $1(1 \%)$ & $3(7.5 \%)$ \\
Chronic rejection/CAN, n (\%) & $92(28 \%)$ & $132(26 \%)$ & $32(35 \%)$ & $16(40 \%)$ \\
Death with function, n (\%) & $176(53 \%)$ & $260(51 \%)$ & $33(36 \%)$ & $12(30 \%)$ \\
Recurrent disease, n (\%) & $10(3 \%)$ & $32(6 \%)$ & $3(3 \%)$ & $1(3 \%)$ \\
De novo disease, n $(\%)$ & $3(1 \%)$ & $1(0.2 \%)$ & $1(1 \%)$ & -- \\
Noncompliance, n $(\%)$ & $7(2 \%)$ & $18(4 \%)$ & $2(2 \%)$ & $4(10 \%)$ \\
Unknown, n $(\%)$ & 22 & 30 & 10 & 3 \\
CNI toxicity, $(\%)$ & $2(1 \%)$ & -- & -- & - \\
Other, n $(\%)$ & $17(5 \%)$ & $29(6 \%)$ & $9(10 \%)$ & $1(3 \%)$ \\
\hline
\end{tabular}

Legend:

$\mathrm{CAN}=$ Chronic allograft nephropathy

$\mathrm{DD}=$ Deceased donor

$\mathrm{LD}=$ Living donor

$\mathrm{CNI}=$ calcineurin inhibitor

(= late technical, malignancy, infection, pre-renal) 
Table 4

Primary Causes of Graft Loss after 10 Years, by Era and Donor Source (Primary Transplant Recipients)

\begin{tabular}{lcccc}
\hline & Era 1 (through 1983) & \multicolumn{2}{c}{ Era 2 (1984 on) } \\
& DD (n=167) & LD (n=341) & DD (n=153) & LD (n=154) \\
Acute rejection (AR), n (\%) & $1(.6 \%)$ & $1(.3 \%)$ & $1(1 \%)$ & $4(2 \%)$ \\
Chronic rejection (CAN), n (\%) & $50(30 \%)$ & $92(27 \%)$ & $42(27 \%)$ & $60(39 \%)$ \\
Death with function, n (\%) & $90(54 \%)$ & $206(60 \%)$ & $86(52 \%)$ & $54(33 \%)$ \\
Recurrent disease, n (\%) & $10(6 \%)$ & $26(8 \%)$ & $4(2 \%)$ & $11(7 \%)$ \\
De novo disease, n (\%) & $2(1 \%)$ & $1(.3 \%)$ & $1(1 \%)$ & -- \\
Noncompliance, n (\%) & $5(3 \%)$ & $12(4 \%)$ & $2(1 \%)$ & $6(4 \%)$ \\
CNI toxicity, n (\%) & -- & -- & $2(1 \%)$ & - \\
Unknown, $(\%)$ & $4(2 \%)$ & $8(2 \%)$ & $3(2 \%)$ & $6(4 \%)$ \\
Other, n $(\%)$ & & & & \\
\hline
\end{tabular}

Legend:

CAN = Chronic allograft nephropathy

$\mathrm{DD}=$ Deceased donor

$\mathrm{LD}=$ Living donor

$\mathrm{CNI}=$ Calcineurin inhibitor 


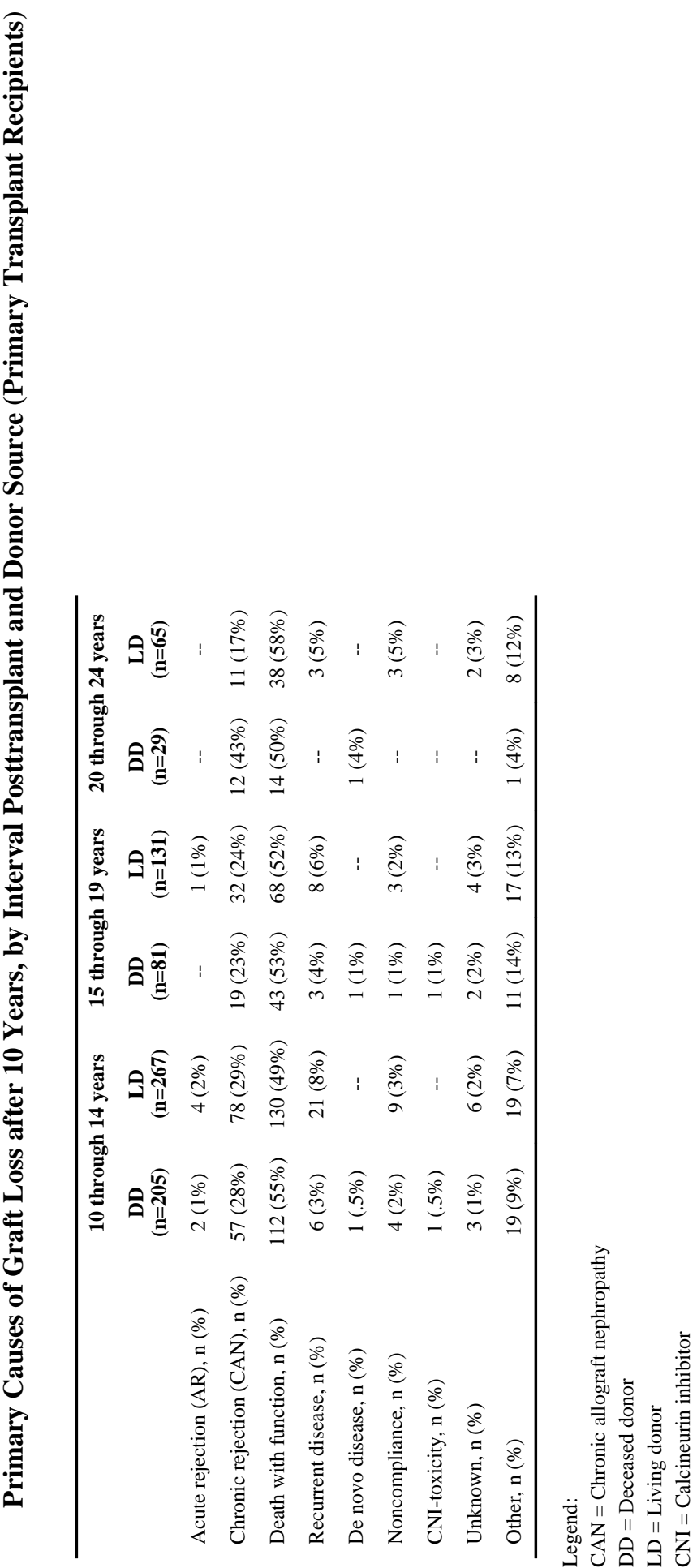

Am J Transplant. Author manuscript; available in PMC 2009 November 1. 
Table 6

Primary Causes of Death with Function after 10 Years, by Transplant Number and Donor Source (All Recipients)

\begin{tabular}{|c|c|c|c|c|}
\hline & Primary DD $(n=176)$ & Primary LD $(n=260)$ & Retransplant DD $(\mathrm{n}=33)$ & Retransplant LD $(n=12)$ \\
\hline Infection & $22(13 \%)$ & $24(9 \%)$ & $3(9 \%)$ & -- \\
\hline Bacterial, n (\%) & $4(2 \%)$ & $\rightarrow 6(2 \%)$ & $1(3 \%)$ & -- \\
\hline Viral, n (\%) & -- & $\rightarrow--$ & $1(3 \%)$ & -- \\
\hline Fungal, n (\%) & $3(2 \%)$ & $\rightarrow 1(0.4 \%)$ & -- & -- \\
\hline Mixed, n (\%) & $12(7 \%)$ & $\rightarrow 9(3 \%)$ & -- & -- \\
\hline Unknown, n (\%) & $3(2 \%)$ & $\rightarrow 8(3 \%)$ & $1(3 \%)$ & -- \\
\hline CVD & $61(35 \%)$ & $100(38 \%)$ & $10(30 \%)$ & $5(42 \%)$ \\
\hline CVA, n (\%) & $14(8 \%)$ & $17(7 \%)$ & $3(9 \%)$ & $1(8 \%)$ \\
\hline MI, n (\%) & $12(7 \%)$ & $22(8 \%)$ & $3(9 \%)$ & -- \\
\hline Other, $\mathrm{n}(\%)$ & $17(10 \%)$ & $32(13 \%)$ & $1(3 \%)$ & $2(17 \%)$ \\
\hline Sudden death at home, $\mathrm{n}(\%)$ & $18(10 \%)$ & $29(11 \%)$ & $3(9 \%)$ & $2(17 \%)$ \\
\hline Liver failure & $5(3 \%)$ & $13(5 \%)$ & $1(3 \%)$ & -- \\
\hline Respiratory disease & $5(3 \%)$ & $16(6 \%)$ & -- & -- \\
\hline Suicide & $1(.6 \%)$ & $2(1 \%)$ & -- & -- \\
\hline \multicolumn{5}{|l|}{ Malignancy } \\
\hline Nonlymphoma, n (\%) & $29(22 \%)$ & $47(18 \%)$ & $7(21 \%)$ & $4(33 \%)$ \\
\hline Lymphoma, n (\%) & $5(3 \%)$ & $10(4 \%)$ & $2(6 \%)$ & $1(8 \%)$ \\
\hline Unknown & $15(9 \%)$ & $13(5 \%)$ & $1(3 \%)$ & $1(8 \%)$ \\
\hline Other & $33(19 \%)$ & $36(14 \%)$ & $9(27 \%)$ & $1(8 \%)$ \\
\hline
\end{tabular}

Legend:

$\mathrm{DD}=$ Deceased donor

$\mathrm{LD}=$ Living donor

$\mathrm{CVA}=$ Cardiovascular accident

$\mathrm{MI}=$ Myocardial infarction

$\mathrm{CVD}=$ Cardiovascular disease 
Table 9

Mean $( \pm$ SD) Serum Creatinine Level in Transplant Survivors with $\geq 10$ Years of Graft Function

\begin{tabular}{cccc}
\hline & Time Posttransplant & $\mathbf{n}$ & Mean Creatinine Level \\
All & $1 \mathrm{yr}$ & 1094 & $1.4 \pm .5$ \\
$5 \mathrm{yr}$ & 1231 & $1.5 \pm .5$ \\
$10 \mathrm{yr}$ & 1254 & $1.7 \pm .8$ \\
$15 \mathrm{yr}$ & 537 & $1.7 \pm .9$ \\
$20 \mathrm{yr}$ & 328 & $1.5 \pm 1$ \\
$22 \mathrm{yr}$ & 265 & $1.5 \pm 1$ \\
$25 \mathrm{yr}$ & 173 & $1.6 \pm 1$ \\
\hline
\end{tabular}


Table 10

Comorbidities at 20 Years Posttransplant, by Transplant Number and Diabetic Status (All Recipients)

\begin{tabular}{|c|c|c|c|c|}
\hline & \multicolumn{4}{|c|}{ 1st Transplant } \\
\hline & \multicolumn{2}{|c|}{ Diabetics } & \multicolumn{2}{|c|}{ Diabetics } \\
\hline & LD & DD & LD & DD \\
\hline Skin cancer & $36 \%$ & $49 \%$ & $41 \%$ & $56 \%$ \\
\hline Nonskin (non-PTLD) cancer & $10 \%$ & $23 \%$ & $14 \%$ & $22 \%$ \\
\hline PTLD & $2 \%$ & $5 \%$ & $3 \%$ & $7 \%$ \\
\hline CVD & $26 \%$ & $33 \%$ & $56 \%$ & $50 \%$ \\
\hline Cerebrovascular disease & $5 \%$ & $14 \%$ & $21 \%$ & $12 \%$ \\
\hline \multirow[t]{4}{*}{ Peripheral vascular disease } & $12 \%$ & $13 \%$ & $35 \%$ & $32 \%$ \\
\hline & \multicolumn{4}{|c|}{ Retransplant } \\
\hline & \multicolumn{2}{|c|}{ Nondiabetics } & \multicolumn{2}{|c|}{ Nondiabetics } \\
\hline & $\mathrm{LD}$ & $\mathrm{DD}$ & $\mathrm{LD}$ & $\mathrm{DD}$ \\
\hline Skin cancer & $51 \%$ & $38 \%$ & -- & -- \\
\hline Nonskin (non PTLD) cancer & $11 \%$ & $33 \%$ & -- & -- \\
\hline PTLD & $0 \%$ & $7 \%$ & -- & -- \\
\hline CVD & $20 \%$ & $42 \%$ & -- & -- \\
\hline Cerebrovascular disease & $2 \%$ & $29 \%$ & -- & -- \\
\hline Peripheral vascular disease & $15 \%$ & $24 \%$ & -- & -- \\
\hline
\end{tabular}

Legend:

$\mathrm{LD}=$ Living donor

$\mathrm{DD}=$ Deceased donor

PTLD = Posttransplant lymphoproliferative disease

$\mathrm{CVD}=$ Cardiovascular disease 